\title{
INCLUSÃO ESCOLAR DO PORTADOR DE PARALISIA CEREBRAL: ATITUDES DE PROFESSORES DO ENSINO FUNDAMENTAL
}

INCLUSION OF INDIVIDUALS WITH CEREBRAL PALSY IN SCHOOL: ELEMENTARY

SCHOOL TEACHERS' ATTITUDES

\author{
Claudia GOMES 1
}

Altemir José Gonçalves BARBOSA²

\begin{abstract}
RESUMO: as atitudes em relação às pessoas com as necessidades especiais representam um dos mais importantes fatores para o sucesso da escola inclusiva. Para avaliar as atitudes do professor quanto à inclusão de portadores de paralisia cerebral (PPC), um questionário com uma escala de atitude foi aplicado em 68 professores de ensino fundamental. Foi evidenciada discordância com relação à inclusão de PPC na escola. A análise fatorial levou a seis fatores que podem explicar tais atitudes: como ensinar PPC em classes normais; sentimentos e emoções de professores na presença de PPC; contato com os PPC; o tipo de educação mais adequado para os PPC; rendimento escolar da sala de aula com a presença de um PPC; e preconceito na sala de aula. Dissonância entre as dimensões afetiva, cognitiva e denotativa das atitudes dos professores foi constatada, a discordância e a dissonância evidenciadas podem representar barreiras quanto à inclusão escolar de PPC.
\end{abstract}

PALAVRAS-CHAVE: inclusão; paralisia cerebral; atitudes; professores.

ABSTRACT: attitudes toward people with special needs represent one of the most important factors for the success of inclusive schooling. To evaluate teachers' attitudes toward the inclusion of individuals with cerebral palsy (ICP) in regular schools, a questionnaire with an attitude scale was applied to 68 elementary public schools teachers. Disagreement regarding school inclusion of ICPs was shown. A factor analysis led to identification of six factors that can explain such attitudes: how to teach ICPs in the regular classroom; teachers' feelings and emotions in the presence of ICPs; previous contact with the ICPs; the most adequate type of education for the ICPs; school achievement of classmates of an ICP; and prejudice in the classroom. Dissonance among affective, cognitive e denotative dimensions of the teachers' attitudes was noted; both disagreement and dissonance shown through this study may represent barriers to the inclusion of the ICPs in school.

KEYWORDS: inclusion; cerebral palsy; attitudes; teachers.

\section{INTRODUÇÃO}

O direito de toda criança à educação, consignado pela Declaração Universal dos Direitos Humanos (UNITED NATIONS, 1948), foi reiterado pela Declaração Mundial sobre Educação para Todos (UNESCO, 1990). Mais recentemente, com a Declaração Mundial de Salamanca (UNESCO, 1994), este

\footnotetext{
${ }^{1}$ Psicóloga pela Universidade Braz Cubas (Mogi das Cruzes - SP), Mestre em Psicologia Escolar (PUC-Campinas), Doutoranda em Psicologia como Profissão e Ciência (PUC-Campinas). End.: Rua Particular, 25 -

Bairro: Brás Cubas, Mogi das Cruzes/SP - CEP: 08740-260. E-mail: claudiagomes.psi@bol.com.br

${ }^{2}$ Mestre em Psicologia Escolar (PUC-Campinas), Doutor em Psicologia como Profissão e Ciência (PUC-Campinas), Professor e supervisor de estágio em Psicologia Escolar (USJT/UBC), Coordenador de Núcleos de Pesquisa da USJT. Rua Doutor Andrade, 12 - Penha, São Paulo/SP - CEP: 03733- 190.E-mail: altgonc@uol.com.br
} 
direito também foi assegurado para um segmento escolar que, até então, era pouco considerado: trata-se dos alunos portadores de necessidades educacionais especiais (PNEE).

No Brasil, um passo importante para assegurar o direito à educação sem exclusão para os PNEE se deu com a promulgação da lei n. ${ }^{\circ}$ 9394/96 - Nova Lei de Diretrizes e Bases Nacional (LDB) (BRASIL, 1996). Em seu Artigo 4. ${ }^{\circ}$, a LDB determina que deve haver "atendimento educacional especializado gratuito aos educandos com necessidades especiais, preferencialmente na rede regular de ensino", e, no seu Artigo 58. ${ }^{\circ}$, estabelece, também, que educação especial é "a modalidade de educação escolar, oferecida preferencialmente na rede regular de ensino, para educandos portadores de necessidades especiais".

Porém, não basta a presença dos PNEEs em escolas regulares, excluídos em salas especiais. As transformações ocorridas no meio educacional e na legislação que rege o sistema educacional brasileiro deixam clara a necessidade de incluir todos os alunos PNEEs nas salas de aula regulares das redes pública e particular de ensino. Parte-se do princípio fundamental de que todos os alunos devem ser respeitados em suas diferenças e características, sejam elas quais forem. Todos os alunos devem ser incluídos em arranjos educacionais feitos para a maioria das crianças; sempre que possível, devem aprender juntas, independentemente de dificuldades ou limitações que possam ter, para que desenvolvam tanto conhecimentos acadêmicos quanto estratégias de convivência que amenizem suas limitações frente à sociedade, fortalecendo a amizade, o companheirismo, a colaboração e fundamentalmente a aceitação entre todos (MANTOAN, 1997; UNESCO, 1994).

Um dos grupos de PNEEs contemplados com as modificações que se deram na segunda metade do século passado no âmbito educacional é o de portadores de paralisia cerebral (PPC). Estima-se que a paralisia cerebral ocorre na proporção de um caso para cada 1000 nascimentos (GOMES, SANTOS, UBIRATAM, SILVA, 2001). Trata-se de pessoas que podem apresentar características deficitárias bastante acentuadas. Além do comprometimento motor que é a característica marcante da deficiência, os déficits dos PPCs podem estar freqüentemente associados a problemas de fala, visão e audição, a vários tipos de distúrbios de percepção, além de certo grau de retardo mental e/ou epilepsia (LAMONICA, CHIARI, PEREIRA, 2002; PATO, SOUZA, LEITE, 2002; DINIZ, 1996; BOBATH, BOBATH, 1989).

No Brasil, já existem condições legais suficientes para que a inclusão escolar dos PNEEs, inclusive dos PPCs, ocorra. No entanto, a concretização deste processo tem esbarrado em uma série de dificuldades. Miles (2000) indica que, em diversas culturas e contextos, as barreiras para a inclusão escolar podem estar relacionadas às pessoas (professores, pais etc.) direta ou indiretamente envolvidas, à ausência de recursos financeiros e materiais, à falta de conhecimento e informação e às características do próprio contexto (pobreza etc.). 
A existência de barreiras a serem transpostas para efetivação da proposta escolar inclusiva é compreensível, uma vez que se trata de um processo um tanto quanto recente no Brasil e ainda em andamento. Os percalços ficam ainda mais evidentes se se considerarem as limitações do sistema público de educação brasileiro. A inadequação das instalações e dependências de parcela expressiva das escolas, uma vez que não se contemplam espaços e condições para portadores de déficits motores, o despreparo do docente para lidar com PNEEs em geral, a carência de materiais básicos (livros etc.) e de recursos tecnológicos avançados como computadores, a presença de uma prática pedagógica que não contempla a diversidade de necessidades educacionais e a ausência de equipes de apoio representam uma pequena amostra das barreiras a serem superadas na escola pública brasileira para que o processo de inclusão escolar de PPCs e de outros PNEEs se torne uma realidade.

Trata-se de limitações concretas e amplamente reconhecidas. No entanto, elas não devem imobilizar a busca por uma escola inclusiva.

Parece existir, porém, no contexto brasileiro, uma barreira que é pouco enfatizada na literatura científica, que é relevada a um segundo plano pelos profissionais (professores, pesquisadores, especialistas etc.) da educação e que tem gerado uma inércia neste âmbito: as atitudes em relação à inclusão escolar. "Atitude é uma variável-chave para determinar o sucesso da educação inclusiva" (Kuester, 2000) e pode ser definida como uma avaliação sumária -- cognitiva e afetiva -- de um objeto psicológico de tal forma que ele será considerado bom ou ruim, nocivo ou benéfico, agradável ou desagradável, desejável ou indesejável (AJZEN, 2001), que gera uma disposição para responder -- dimensão conotativa das atitudes -- de maneira favorável ou desfavorável a este objeto (AJZEN, 2002).

Atitudes negativas levam as pessoas a dizer: "Nós não temos... portanto nós não podemos fazer..." . (...) Contudo, se mudarmos isso dizendo: "Nós somos... portanto nós fazemos", é possível transpormos a mais aparentemente insuperável das barreiras. Devemos usar o que temos em qualquer contexto em que estejamos trabalhando. Pessoas competentes são pessoas cheias de recursos (MILES, 2000, p.13).

Mantoan (2000) afirma que as barreiras relacionadas às atitudes negativas levam as pessoas a responderem desfavoravelmente à inclusão escolar e aos PNEEs, a partir de um certo valor. Vários estudos (por exemplo, KUESTER, 2000; MARAIS, 2000; MARSHALL, 2000; SADEK, SADEK, 2000; STANCIC, 2000; BAYLISS, AVRADIMIS, 2000; WOODRUM, LOMBARDI, 2000) têm demonstrado o quanto as atitudes de professores, diretores, pais, estudantes, psicólogos e outras pessoas são fundamentais para o processo de inclusão escolar.

Estes e outros estudos têm dado uma ênfase especial às atitudes dos docentes, pois, de acordo com Kuester (2000), um dos fatores mais importantes para o sucesso da inclusão de um estudante PNEE diz respeito à interação deste com o professor. Dentre as variáveis que influenciam as atitudes dos professores, a literatura científica tem se voltado para o tipo de professor, a natureza da 
necessidade especial, o gênero do docente, a experiência do professor, a experiência e o treinamento para trabalhar com PNEEs, a presença de recursos necessários, o conhecimento sobre inclusão, o suporte familiar, atitudes em relação ao ensino em geral (ver, por exemplo, BAYLISS. AVRADIMIS, 2000; KUESTER, 2000; MARAIS, 2000; STANCIC, 2000).

Evidenciada a importância das atitudes para o sucesso da educação inclusiva e constatada a carência de estudos que abordem especificamente as atitudes de professores em relação à inclusão escolar de PPCs, este estudo objetivou descrever as atitudes de docentes de salas regulares de ensino público fundamental perante a possível inclusão de um PPC em sua turma.

\section{MÉTodo \\ Participantes}

Participou deste estudo uma amostra não probabilística de 68 docentes de 1. à $4 .^{\text {a }}$ série do ensino fundamental da Rede Municipal de Ensino da cidade de Mogi das Cruzes / SP, a escolha do local se deve, ao momento propicio de discussões acerca da inclusão escolar, apontada pelas políticas educacionais do município. Quanto aos participantes, 97,06\% dos participantes eram do sexo feminino e $2,94 \%$, do sexo masculino. A idade média dos professores em anos foi de 33,41, sendo que a idade mínima foi de 25 anos e a máxima, de 55 anos, com um desvio padrão de 6,95. Em média, os participantes lecionam há 11 anos e cinco meses.

Dos participantes que indicaram a série que lecionam $(\mathrm{N}=66), 31,82 \%$ ensinam para 1 . $^{\mathrm{a}}$ série, $24,24 \%$ para a 2 . $^{\mathrm{a}}$ série, $22,73 \%$ para a 3 . $^{\mathrm{a}}$ série e $21,21 \%$ para a $4 .^{\text {a }}$ série.

Verificou-se que 70,59\% dos participantes tinham formação equivalente à graduação, 16,18\%, apenas ao ensino médio, e 13,24\%, à pós-graduação.

\section{Material}

Utilizou-se como instrumento um questionário composto por 19 questões mistas, que enfatizavam questões relativas a inclusão escolar de alunos portadores de necessidades especiais (formação, conhecimento, procedimentos de ensino-aprendizagem, etc) e uma escala de atitudes tipo Likert com 20 itens, com quatro pontos: "concordo", "concordo parcialmente", "discordo parcialmente" e "discordo", especificamente, frente as atitudes dos professores quanto a inclusão escolar de alunos portadores de necessidades especiais. Também compunha o instrumento uma folha de rosto contendo as instruções para o preenchimento do questionário e o termo de consentimento livre e esclarecido.

A escala foi elaborada a partir da revisão de literatura e, antes da coleta de dados, foi feita uma aplicação piloto em 20 professores de ensino fundamental. Após esta etapa, consideraram-se apenas os itens mais adequados (clareza, redação 
etc.) para compor a escala definitiva, culminando no instrumento que foi usado no estudo.

\section{Procedimentos}

Após autorização da Secretaria Municipal de Educação, o instrumento foi entregue à direção das escolas, que o repassou aos docentes. Foi dado um intervalo de tempo de uma semana para que os sujeitos respondessem ao questionário. Após este período, os Autores recolheram os questionários preenchidos.

Para tratamento qualitativo dos dados oriundos das questões dissertativas, decorrentes das alternativas das questões mistas, foi empregada análise dos conteúdos apontados, para a categorização das questões e posterior análise estatística das respostas. Com o intuito de avaliar a confiabilidade deste procedimento, contou-se com a colaboração de dois juízes independentes e qualificados. Obteve-se uma concordância de $100 \%$ na questão em que os participantes eram solicitados a indicar as características dos PPCs que mais chamam a atenção. Quanto aos aspectos favoráveis $\left(93,50 \% ; \mathrm{c}^{2}{ }_{\mathrm{o}}=34,78 ; \mathrm{ngl}=1\right.$; $\mathrm{p}$ $=0,00)$ e contrários $\left(94,00 \% ; c^{2}{ }_{0}=93,63 ; n g l=1 ; p=0,00\right)$ à inclusão escolar do PPC, também foram obtidos percentuais médios de concordância estatisticamente significativos.

\section{Resultados E Discussão}

Quanto à participação em cursos ou palestras relacionados ao processo de inclusão escolar dos PNEEs, entre eles dos PPCs, constatou-se que a maioria $\left(76,47 \% ; c^{2}=19,05 ; n g l=1 ; p=0,00\right)$ dos docentes não participaram deste tipo de evento, sendo que nenhum dos participantes recebeu qualquer tipo de preparação para trabalhar especificamente com PPCs. Corrobora-se, desta forma, que atualmente uma das barreiras a serem transpostas pela política educacional inclusiva é a falta de recursos humanos habilitados para atuar nesta questão.

Para que a inclusão escolar ocorra efetivamente, é necessário um aprimoramento constante dos professores, com o domínio de instrumentos e referenciais que façam evoluir as práticas pedagógicas. A capacitação de todos os educadores e o aprimoramento dos demais profissionais da escola, seja através de palestras abrangentes ou treinamentos específicos, são o ponto fundamental para a efetivação do processo inclusivo nas escolas (UNESCO, 1994). Os professores devem ter conhecimento e habilidades necessários para selecionar e adaptar o currículo e o método de ensino de acordo com as necessidades individuais dos estudantes (ERIC, 1993). Esta preparação não deve se restringir aos métodos e recursos especializados, mas sim propiciar orientação que leve ao desenvolvimento de competências e habilidades, que permitam a exploração e o domínio cada vez mais amplo das práticas docentes (MANTOAN, 1997a). 
Verificou-se que a maioria $\left(c^{2}=24,82 ; n g l=2 ; p=0,00\right)$ dos participantes que expressaram o seu grau de concordância com a inclusão escolar de PPCs ( $\mathrm{N}=$ 66) tende a discordar $(59,09 \%)$ deste processo. Há, ainda, 9,09\% que discordam parcialmente, sendo que apenas $31,82 \%$ concordam parcialmente com este processo. Dada a carência de projetos que proporcionam preparação profissional aos professores, torna-se compreensível esta resistência por parte de muitos docentes quanto à inclusão escolar de PPCs, pois, segundo Basil (1995), é imprescindível que os docentes dominem sistemas e técnicas que, somados aos recursos terapêuticos e educacionais apropriados, sejam aplicados para garantir um desenvolvimento do aluno. Porém, isto só poderá ser alcançado se houver mudança de atitudes e uma formação adequada dos professores que educarão esses alunos.

A primeira percepção que os professores devem ter frente a um aluno portador de paralisia cerebral é a de que tem diante de si um aluno que deve ser ajudado, assim como todos os demais, aproveitando e explorando ao máximo suas potencialidades e promovendo o seu desenvolvimento. As necessidades especiais desses alunos devem ser vistas mais como um desafio do que como obstáculos (BASIL, 1995).

É indispensável que estes profissionais repensem seus atos educativos, objetivando transformar a realidade, e, sobretudo, que sejam capazes de fazer com que a inclusão escolar aumente as oportunidades que têm sido oferecidas aos PNEEs, entre eles os PPCs (MEDEIROS, 2002; ANDRETTO, 2001).

Não foi constatada correlação entre o grau de concordância dos professores com inclusão escolar dos PPCs e a experiência profissional em ano dos docentes $\left(\mathrm{r}_{\mathrm{so}}=-0,09 ; \mathrm{N}=66 ; \mathrm{p}=0,47\right)$. O grau médio de concordância dos docentes quanto à inclusão escolar do PPC também não apresentou diferença significante em função da série em que os participantes lecionavam $\left(c^{2}{ }_{o}=0,30 ; n g l=3 ; p=\right.$ 0,96). O fato de os professores terem ou não participado de cursos ou palestras sobre educação inclusiva $\left(U_{o}=346,560 ; p=0,53\right)$, conhecerem ou não PPCs $\left(U_{o}=\right.$ $461,50 ; p=0,73)$, terem ou não trabalhado com PPCs $\left(U_{o}=148,50 ; p=0,46\right)$, conhecerem ou não as características físicas dos PPCs $\left(U_{o}=253,50 ; p=0,44\right)$ não implicaram diferenças significantes no grau médio de concordância quanto à inclusão escolar desta necessidade educativa especial.

Dentre as respostas dadas apenas pelos 12 professores que afirmaram conhecer as características dos PPCs (Tabela 1), prevaleceram as relacionadas aos distúrbios de comunicação $(38,24 \%)$, seguidas pelas que indicavam distúrbios motores $(35,29 \%)$. 
TABELA 1 - Características dos PPCs que mais chamam a atenção dos participantes

\begin{tabular}{lcc}
\hline \multicolumn{1}{c}{ Características dos PPCs } & f & \% \\
\hline Distúrbios da comunicação & 13 & 38,24 \\
Distúrbios motores & 12 & 35,29 \\
Características musculares dos membros & 4 & 11,77 \\
Flacidez da musculatura orofacial & 2 & 5,88 \\
Ausência de controle das necessidades fisiológicas & 1 & 2,94 \\
Ausência de paladar & 1 & 2,94 \\
Distúrbios da memória & 1 & 2,94 \\
\hline Total & $\mathbf{3 4}$ & $\mathbf{1 0 0 , 0}$ \\
\hline
\end{tabular}

$\mathrm{N}=11$, um participante não respondeu à questão.

De forma geral, constata-se que, entre as características dos PPCs conhecidas e citadas pelos professores, a maioria enfoca aspectos "negativos" desta necessidade educacional especial e que, para o professor, se mal preparado, podem representar "impedimentos" para que o processo de inclusão escolar destes alunos se efetive.

A Tabela 2 apresenta os pontos favoráveis à inclusão escolar do PPC, indicados pelos docentes. Constata-se nela que a socialização do PPC, com 67,40\% das respostas, é a principal contribuição que a escola inclusiva pode dar a este PNEE no ponto de vista dos professores.

TABELA 2 - Aspectos contrários e favoráveis à inclusão escolar do PPC.

\begin{tabular}{lrr|lrc}
\hline \multicolumn{1}{c}{ Aspectos Contrários } & f & $\mathbf{\%}$ & \multicolumn{1}{c}{ Aspectos Favoráveis } & f & \% \\
\hline $\begin{array}{l}\text { Formação deficitária dos } \\
\text { docentes }\end{array}$ & 45 & 37,50 & Socialização & 31 & 67,40 \\
Excesso de alunos & 21 & 17,50 & Diminuir preconceitos & 6 & 13,04 \\
Preconceitos & 18 & 15,00 & $\begin{array}{l}\text { Novas experiências e } \\
\text { possibilidades }\end{array}$ & 4 & 8,70 \\
Trabalho diferenciado & 12 & 10,00 & Inclusão escolar & 2 & 4,35 \\
Instalações inadequadas & 11 & 9,17 & $\begin{array}{l}\text { Ausência de pontos } \\
\text { favoráveis }\end{array}$ & 1 & 2,17 \\
$\begin{array}{l}\text { Ausência de apoio } \\
\text { institucional }\end{array}$ & 9 & 7,50 & Desenvolvimento cognitivo & 1 & 2,17 \\
Falta de recursos & 4 & 3,33 & Desenvolvimento motor & 1 & 2,17 \\
\hline Total & $\mathbf{1 2 0}$ & $\mathbf{1 0 0}$ & Total & $\mathbf{4 6}$ & $\mathbf{1 0 0 , 0}$ \\
\hline
\end{tabular}

$\mathrm{N}=48,20$ participantes não responderam à questão. $\mathrm{N}=30,38$ participantes não responderam à questão. 
Sendo assim, pôde-se constatar que, de modo geral, a inclusão escolar do PPC é vista pelos professores como uma ação muito mais "humanitária" do que realmente educacional. A proposta inclusiva, para muitos professores, leva em consideração apenas a possibilidade de interação social destes PNEEs, visando muito mais ao "bem-estar" social destes alunos, desconsiderando as possibilidades de um real desenvolvimento cognitivo (MARQUES, OLIVEIRA, SANTOS, 1998).

O pequeno número de docentes que indicaram pontos favoráveis quanto à inclusão escolar de PPCs, apenas 44,11\% da amostra de participantes, gera preocupações, já que o número de respondentes, quando se tratava de pontos contrários a este processo (Tabela 3), foi bem maior (70,58\%). A formação deficitária dos professores (37,50\%) foi indicada como o principal impedimento para que estes PNEEs sejam incluídos em escolas regulares. Esta categoria englobou respostas que faziam referência à "falta de experiência", ao "professor não capacitado" e à "falta de preparo do professor". Além de profissionais qualificados, a concretização da educação inclusiva demanda mudanças em múltiplos aspectos da escolarização. Dentre alterações ensejadas estão aquelas relacionadas aos prédios, à organização escolar, à filosofia da escola, às formas de avaliação e às atividades extracurriculares (ORGANIZAÇÃO DAS NAÇÕES UNIDAS, 1996).

Não só as barreiras explícitas como a falta de estrutura predial, a desorganização escolar, a ausência de recursos e a inadequação dos métodos educacionais devem ser analisadas, mas também e essencialmente os sentimentos dos professores quanto à inclusão escolar de uma nova clientela (MANTOAN, 1997). Assim, mostra-se adequado e necessário analisar as atitudes dos docentes em relação à possível presença de um PPC em sua sala de aula regular.

A maioria dos docentes discorda da inclusão escolar do PPC (57,35\%; $\left.\mathrm{c}^{2}{ }_{\mathrm{o}}=21,38 ; \mathrm{ngl}=2 ; \mathrm{p}=0,00\right)$. Há, ainda, $11,76 \%$ dos professores que discordam parcialmente deste processo, sendo que apenas 30,88\% concordam parcialmente que estes PNEEs freqüentem salas de aula regulares.

Ao se computar o escore médio geral dos participantes na escala de atitudes em relação à inclusão escolar do PPC (EAIEC-PPC), obteve-se uma média de 2,71 pontos, com desvio padrão de 0,40 , sendo o mínimo obtido igual a 1,75 e o máximo igual a 3,45 . Se se considerar que a escala possui quatro pontos $(1=$ concordo, 2 = concordo parcialmente, $3=$ discordo parcialmente e $4=$ discordo) e arredondar a média dos participantes, verificar-se-á que estas atitudes tendem a ser negativas, isto é, de discordância parcial.

Ao se correlacionarem os resultados da EAIEC-PPC com os obtidos na questão que tratou da concordância com o processo de inclusão escolar dos PPCs, obteve-se correlação positiva $\left(r_{\text {so }}=0,26 ; p=0,03 ; \mathrm{N}=68\right)$. Este resultado, de certa forma, evidencia a adequação da escala e ressalta a importância das atitudes para o êxito da educação inclusiva, pois, até certo ponto, verifica-se neste resultado que elas predizem o comportamento em relação a incluir este PNEE em sala de aula regular. 
Ao se compararem os resultados da EAIEC-PPC com algumas variáveis pesquisadas, constatou-se que:

- Os participantes que afirmam conhecer as características de um PPC têm atitudes mais positivas que os que as desconhecem $\left(\mathrm{U}_{\mathrm{o}}=163,00 ; \mathrm{p}=0,01\right)$;

- $\mathrm{O}$ fato de os professores terem participado de palestras não fez com que suas atitudes diferissem $\left(\mathrm{U}_{\mathrm{o}}=309,00 ; \mathrm{p}=0,12\right)$;

- A experiência profissional prévia como educador de PPCs não implicou atitudes diferentes daqueles que não tiveram esta oportunidade $\left(U_{0}=118,00\right.$; $\mathrm{p}=0,06)$;

- Aqueles docentes que julgam ser de sua responsabilidade educar PNEEs apresentaram atitudes mais positivas $\left(\mathrm{U}_{\mathrm{o}}=188,00 ; \mathrm{p}=0,01\right)$.

A efetivação de uma prática educacional inclusiva requer necessariamente que todos os professores e outros profissionais da educação sejam dotados tanto de materiais, instrumentos e referenciais teóricos e práticos, para que possam adaptar suas práticas pedagógicas para incluir o aluno PPC na escola regular, quanto de conhecimentos sobre diferenças individuais e, acima de tudo, de capacidade para trabalhar com a diversidade, seja ela física, cognitiva ou social, dentro da escola (CAVALCANTE, 2000; MARQUES, OLIVEIRA, SANTOS, 1998). Para isto, é necessária preparação prévia quanto ao processo de inclusão escolar. Todavia, os resultados evidenciam que não basta freqüentar cursos, palestras etc. como eles são atualmente. Há a necessidade de reformulá-los, para que possam se tornar impulsionadores para o desenvolvimento de atitudes positivas quanto à educação inclusiva.

Cabe ressaltar que a capacitação profissional só poderá apresentar resultados positivos, quando forem revistos e compreendidos, primeiramente, os posicionamentos e as atitudes dos professores frente à própria atuação profissional. Assim, se os docentes não julgam ser de sua responsabilidade educar toda e qualquer pessoa, pouco útil é capacitá-lo com os mais avançados conhecimentos teóricos e práticos.

A análise fatorial da EAIEC-PPC extraiu seis fatores (Tabela 3) que explicam as atitudes dos professores quanto ao processo de inclusão escolar do PPC $(\mathrm{KMO}=0,63 ;$ Teste de Bartlett $=521,10 ; \mathrm{ngl}=190 ; \mathrm{p}=0,00)$. Juntos eles explicam $67,46 \%$ da variância das respostas. 
TABELA 3 - Análise fatorial da EAIEC-PPC.

\begin{tabular}{|c|c|c|c|c|}
\hline Fatores* & Itens $^{* *}$ & $\begin{array}{l}\text { Carga } \\
\text { Fatorial }\end{array}$ & Atitude & $\mathbf{V} \mathbf{E}^{* * *}$ \\
\hline \multirow{5}{*}{$\begin{array}{c}\text { Fator 1: Presença e } \\
\text { manejo do PPC em sala } \\
\text { de aula regular. }\end{array}$} & Aprimoramento de conhecimento dos professores. & 0,81 & + & \multirow{5}{*}{16,22} \\
\hline & $\begin{array}{l}\text { Maior dedicação e tempo de trabalho por causa do } \\
\text { PPC. }\end{array}$ & 0,76 & $+/-$ & \\
\hline & $\begin{array}{l}\text { PPCs podem freqüentar salas regulares apesar de } \\
\text { possuírem locomoção prejudicada. }\end{array}$ & 0,75 & + & \\
\hline & Obrigatoriedade da inclusão do PPC. & 0,60 & $+/-$ & \\
\hline & $\begin{array}{l}\text { PPCs possuem os mesmos direitos dos demais } \\
\text { alunos. }\end{array}$ & 0,59 & + & \\
\hline \multirow{5}{*}{$\begin{array}{l}\text { Fator 2: Sentimentos e } \\
\text { emoções dos professores } \\
\text { frente a um PPC. }\end{array}$} & Um PPC é esquisito. & 0,72 & + & \multirow{5}{*}{12,93} \\
\hline & O olhar de um PPC é desagradável. & 0,68 & + & \\
\hline & O déficit motor de um PPC é muito visível. & 0,62 & + & \\
\hline & $\begin{array}{l}\text { A característica corporal de um PPC é muito } \\
\text { diferente. }\end{array}$ & 0,61 & + & \\
\hline & Alunos PPCs babam. & 0,50 & + & \\
\hline \multirow{4}{*}{$\begin{array}{l}\text { Fator 3: Contato com } \\
\text { um PPC. }\end{array}$} & Sentir-se bem em contato com um PPC. & 0,83 & + & \multirow{4}{*}{11,79} \\
\hline & O PPC é uma boa companhia. & 0,76 & + & \\
\hline & $\begin{array}{l}\text { Presença na sala de aula, quando criança, de um } \\
\text { colega PPC. }\end{array}$ & 0,67 & $+/-$ & \\
\hline & $\begin{array}{l}\text { É desgastante dispensar atenção diferenciada aos } \\
\text { PPCs e atender aos demais alunos. }\end{array}$ & 0,47 & - & \\
\hline \multirow{4}{*}{$\begin{array}{c}\text { Fator 4: Tipo de } \\
\text { educação mais adequada } \\
\text { para um PPC. }\end{array}$} & $\begin{array}{l}\text { PPCs não se adaptam em salas de aula regulares } \\
\text { devido às suas características físicas. }\end{array}$ & 0,79 & - & \multirow{4}{*}{10,78} \\
\hline & PPCs devem freqüentar escolas especializadas. & 0,73 & $+/-$ & \\
\hline & A fala do PPC impossibilita as atividades escolares. & 0,56 & $+/-$ & \\
\hline & Adequação da proposta inclusiva. & 0,55 & - & \\
\hline $\begin{array}{c}\text { Fator 5: Rendimento } \\
\text { escolar de salas } \\
\text { com PPCs. }\end{array}$ & $\begin{array}{l}\text { Rendimento escolar de sala de aula regular com PPC } \\
\text { difere das outras salas. }\end{array}$ & 0,74 & - & 8,45 \\
\hline $\begin{array}{l}\text { Fator 6: Preconceitos } \\
\text { em sala de aula. }\end{array}$ & Saber lidar com preconceitos em sala de aula. & 0,84 & + & 7,25 \\
\hline
\end{tabular}

* Método de extração: Análise de Componentes Principais. Método de Rotação: Quartimax com normalização de Kaiser.

** Os itens da escala aparecem resumidos e sem a inversão (negativo para positivo) efetuada para a análise de dados.

*** Variância explicada pelos fatores. 
Os itens que compõem cada fator foram avaliados para determinar se, na amostra pesquisada, eles representam atitudes positivas $(+)$, negativas $(-)$ ou indefinidas (+/-). Para tanto, consideraram-se discordo e discordo parcialmente como atitudes negativas, e concordo e concordo parcialmente como positivas. Após isto, empregou-se a prova de qui-quadrado para se verificar a prevalência de uma delas.

O fator 1, que trata da presença e do manejo do PPC em sala de aula regular, explica $16,22 \%$ da variância das respostas. Ele é composto por cinco itens, sendo que três deles (aprimoramento de conhecimento dos professores; PPCs possuem locomoção prejudicada; PPCs possuem os mesmos direitos dos demais alunos) são considerados positivamente. Desta forma, apesar de os docentes aparentemente terem atitudes positivas quanto à presença e ao manejo do PPC em sala de aula, há indícios de conflitos e dissonância cognitiva, pois eles concordam que estes PNEEs têm os mesmos direitos dos demais estudantes, mas se dividem quanto a terem estes alunos em suas salas somente se fosse obrigatório.

Os itens agrupados no fator 2 fazem referência aos sentimentos e às emoções dos professores frente a um PPC. Eles salientam a aparência física de tais alunos, como, por exemplo, o ato de babar e possuir um olhar desagradável ou déficit motor muito visível. Em todos os casos foram obtidas atitudes positivas. Desta forma, a imagem corporal do PPC aparentemente não é um fator que influenciaria negativamente o processo de inclusão escolar destes PNEEs. Vale ressaltar que este fator explica $12,93 \%$ da variância das respostas.

Nos itens agrupados no fator 3 (11,79\% da variância das respostas), denominado contado com um PPC, constata-se dissonância nas atitudes dos docentes. Ao mesmo tempo em que se posicionam positivamente em sentir-se bem em contato com um PPC, considerando-o ainda uma boa companhia, suas atitudes mostramse negativas ao considerar a necessidade de se dispensar atenção diferenciada a estes alunos.

O fator 4 - tipo de educação mais adequada para um PPC - explica 10,78\% da variância das respostas. A análise dos itens nele contidos confirma, mais uma vez, a dissonância existente nas atitudes dos professores quanto à questão inclusiva de tais alunos. A inconsistência atitudinal dos docentes neste caso é bastante aparente, pois eles posicionam-se negativamente tanto em relação à adequação da proposta inclusiva, como ao considerarem que os PPCs não se adaptam às salas de aula regulares, porém, tendem a manter-se neutros quanto às afirmações que indicavam que tais alunos deveriam freqüentar escolas especializadas e as que assinavam que a fala destes PNEEs impossibilitaria as atividades escolares. A contradição é evidente, uma vez que estes estudantes "não devem freqüentar apenas escolas especializadas" e, por outro lado, "eles não devem ser educados em sala de aula regular", isto é, não devem ser incluídos. Assim, restam as indagações, não respondidas por este estudo, sobre que tipo de educação deve ser ofertada aos PPCs, talvez, em uma sala especial na escola regular. Se esta última 
afirmação, que aqui é colocada como apenas uma hipótese, for corroborada por outros estudos, confirma-se que os professores não estão imbuídos de ideais inclusivistas.

Já o fator 5 (8,45\% da variância das respostas), composto apenas por um item que trata do rendimento escolar de salas de aula com PPCs incluídos, apresenta atitude negativa. Talvez, a cognição representada por este item possa sinalizar que os docentes buscam superar a dissonância evidenciada nos itens constantes nos outros fatores, pois ela pode servir como uma justificativa para a não inclusão escolar do PPC. "A existência de dissonância, ao ser psicologicamente incômoda, motivará a pessoa para tentar reduzi-la e realizar a consonância" (FESTINGER, 1975: 12).

Desta forma, os participantes buscam conciliar atitudes positivas quanto à presença e ao manejo de PPCs em sala de aula regular, atitudes positivas em relação aos sentimentos e emoções despertados por estes PNEEs e atitudes positivas em relação à presença de preconceito em sala de aula (Fator 6) com atitudes que tendem a ser negativas quando se trata do tipo de educação mais adequada para um PPC. "O indivíduo esforça-se por realizar um estado de coerência consigo mesmo. A tendência de suas opiniões e atitudes, por exemplo, é para existirem em grupos internamente coerentes" (FESTINGER, 1975: 11).

O último fator (6) explica 7,25\% da variância das respostas e inclui somente o item relacionado ao fato de o professor saber lidar com preconceito em sala de aula no caso de inclusão do PPC. Como indicado anteriormente, observouse uma atitude positiva neste caso.

De modo geral, ao se analisarem os itens da EAIEC-PPC, pôde-se constatar que as atitudes negativas estão mais relacionadas à atuação profissional, às metodologias de ensino e às deficiências e carências das práticas educacionais dos próprios professores. Este resultado denota a necessidade de se reformular a prática pedagógica da escola regular para que se efetive o processo de inclusão escolar de PPCs.

Em contrapartida, os itens relacionados às questões que indicam sentimentos e emoções, convivência ou contato com PPC, ou seja, que buscaram levantar os aspectos afetivos ou emocionais das atitudes dos docentes quanto à ação educacional inclusiva, apresentam atitudes positivas.

Na busca de uma consonância entre aspectos cognitivos, afetivos e denotativos de suas atitudes em relação à inclusão escolar de PPCs, as atitudes contrárias à presença deste PNEE são justificadas pela (real) falta de preparo profissional e pela (real) ausência de respaldo oferecido pelos órgãos competentes. Atitudes baseadas em preconceitos, como, por exemplo, "salas regulares que têm PPCs têm um desempenho inferior às que não têm", assim como a ausência de um posicionamento coerente com sua prática profissional, como, por exemplo, assumir responsabilidade para com o atendimento e desenvolvimento de todos os alunos 
indistintamente (MEDEIROS, 2002), são desconsideradas pelos participantes.

A falta de preparo profissional dos docentes e a ausência de suporte por parte de órgãos competentes são fatos já corroborados por várias pesquisas (ver, por exemplo, ERIC, 2002), inclusive esta. Não obstante, somente isto não pode ser usado como expiação para justificar a ausência de uma escola inclusiva no país.

Enquanto os docentes não assumirem o papel de educar a todo e qualquer aluno, modificando e redirecionando sua prática profissional para ações mais igualitárias, isto é, não se posicionarem efetivamente como responsáveis pelo ato de educar também os PNEEs, o professor terá, diante dos PPCs, um obstáculo, e não um estímulo para aproveitar todas as oportunidades de formação permanente, buscando melhorar dia a dia a escolha e o desenvolvimento de estratégias e metodologias de ensino-aprendizagem. Ressalta-se que esta prática constante dotará o professor de uma capacidade de auto-análise de suas próprias práticas pedagógicas, seus impasses e dificuldades, auxiliando-o a converter-se em um bom professor, não somente para o aluno PPC, mas para todos os demais (BASIL, 1995). Para isto, é indispensável que estes profissionais revejam suas próprias percepções, sentimentos, crenças, valores, atitudes e comportamentos.

\section{CONClusão}

Mesmo caracterizados como possuidores de uma formação acadêmica que contempla os objetivos estabelecidos pela legislação brasileira, os docentes participantes desta pesquisa parecem não possuir um preparo profissional adequado para atuar com PPC em suas salas de aula regulares. Ressalta-se que os próprios docentes afirmam não estar capacitados para a atuação em uma escola inclusiva. Apresentaram, inclusive, atitudes negativas quanto à política educacional inclusiva promovida no país.

Constata-se que não só falta preparo profissional, mas também informação quanto à paralisia cerebral. A grande maioria dos professores sequer conhece ou teve contato com um PPC, que, por tratar-se de uma população com padrões e características corporais atípicas e bastante salientadas, requer, necessariamente, uma preparação diferenciada do educador para lidar com estes alunos.

Nos seis fatores que explicam as atitudes dos professores quanto à inclusão escolar do PPC, fica evidenciada a dissonância entre os componentes das atitudes. Nem sempre as dimensões afetiva, cognitiva e denotiva estão consonantes. Há, inclusive, evidências de dissonâncias estritamente cognitivas.

Cabe ressaltar que a dissonância na estruturação das atitudes dos docentes pode estar ligada à falta de preparo profissional, fato este já evidenciado anteriormente. Porém, existe uma questão fundamental a ser considerada, que diz respeito ao fato de parcela significativa dos participantes não considerar ser de 
sua responsabilidade e competência educar alunos PCCs. Este fato evidencia a necessidade de serem revistos, prioritariamente, quais são as crenças, as convicções, os valores e os preconceitos, ou seja, a postura pessoal do docente, para que, desta forma, adquiram atitudes positivas e busquem capacitação profissional para atuar como agentes de inclusão escolar de PNEEs, entre eles os PPCs.

\section{REFERÊNCIAS}

AJZEN, I. Nature and operations of attitudes. Annual Review of Psychology, v 52, p.27-58, 2001.

. Overhead transparencies introduction. Psych 661: Attitudes and Opinions. Disponível em: <http://www-unix.oit.umass.edu/ psyc661/intro.html. Acesso em: 07 de agosto de 2002.

ANDRETTO, Y. T. T. Os impactos iniciais da inclusão da criança deficiente no ensino regular: um estudo sobre a inclusão de criança com paralisia cerebral. 2001 Dissertação (Mestrado) Universidade Presbiteriana Mackenzie, São Paulo.

BASIL, C. Os alunos com paralisia cerebral: desenvolvimento e educação. In COLL, C; PALACIOS, J.; MARCHESI, A. (Orgs.). Desenvolvimento Psicológico e Educação: necessidades educativas especiais e aprendizagem escolar. Porto Alegre: Artes Médicas, 1995. p. 252-271.

BAYLISS, P., AVRAMIDIS, E. Mainstream teacher's attitudes toward the inclusion of students with special educational needs in the ordinary school. INTERNATIONAL SPECIAL EDUCATION CONGRESS, 2000, Manchester. Disponível em: <http:// www.isec2000.org.uk. Acesso em: 15 de novembro de 2002.

BOBATH, B., BOBATH K. Desenvolvimento motor nos diferentes tipos de paralisia cerebral. São Paulo: Manole, 1989.

BRASIL. Lei de Diretrizes e Bases da Educação. Brasília. Disponível em: <http:// www.mec.gov.br/legis/default.shtm. Acesso em: 17 de dezembro de 2002

CAVALCANTE, R. S. C. A inclusão do aluno com necessidades educacionais especiais na sala de aula do ensino regular: o papel do professor. Temas Sobre Desenvolvimento, v 9, n.52, p. 31-35, 2000.

DINIZ, D. Dilemas éticos da vida humana: a trajetória hospitalar de crianças portadoras de paralisia cerebral grave. Caderno de Saúde Pública, v. 12, n. 3, p.12-26, 1996.

ERIC. Including students with disabilities in general education classrooms. ERIC Digest. Disponível em: <http:/ / www.askeric.org/databases/ERIC_Digest/ed358677.html. Acesso em: 8 de março de 2002.

FESTINGER, L. Teoria da dissonância cognitiva. Rio de Janeiro: ZAHAR, 1975.

GOMES, C., SANTOS C. A., UBIRATAM J. S. Paralisia Cerebral. In: LIANZA, S.. Medicina de reabilitação. Rio de Janeiro: Guanabara/Koogan, 2001. p. 281-282.

KUESTER, V. M. 10 years on: have teacher attitudes toward the inclusion if students with disabilities changed. INTERNATIONAL SPECIAL EDUCATION CONGRESS, 2000, Manchester. Disponível em: <http:// www.isec2000.org.uk. Acesso em: 15 de novembro de 2002. 
LAMONICA, D. A. C.; CHIARI, B. M., PEREIRA, L. C. Perda auditiva em indivíduos paralíticos cerebrais: discussão etiológica. Revista Brasileira de Otorrinolaringologia, v. 68, n.1, p. 40-45, 2002.

MANTOAN, M. T. E. A integração de pessoas com deficiência. São Paulo: Senac, 1997.

. Ser ou estar: eis a questão. explicando o déficit intelectual. Rio de Janeiro: WVA, 1997a.

. Toward a school for all. INTERNATIONAL SPECIAL EDUCATION CONGRESS, 2000, Manchester. Disponível em: <http://www.isec2000.org.uk. Acesso em: 15 de novembro de 2002.

MARAIS, J. L. The attitudes of South African teachers toward inclusion: implications for teacher education in the new millennium. INTERNATIONAL SPECIAL EDUCATION CONGRESS, 2000, Manchester. Disponível em: <http:/ / www.isec2000.org.uk. Acesso em: 15 de novembro de 2002.

MARQUES, L. P. OLIVEIRA, L. A.; SANTOS, N. A. S. Integração de paralisados cerebrais: um estudo. Temas Sobre Desenvolvimento, v. 40, p. 16-23, 1998.

MARSHALL, J. Attitudes of PGCE students at the University of Manchester towards childhood speech and language difficulties. INTERNATIONAL SPECIAL EDUCATION CONGRESS, 2000, Manchester. Disponível em: <http:/ / www.isec2000.org.uk. Acesso em: 15 de novembro de 2002.

MEDEIROS, W. A. Representações de professores sobre a educação especial diante da inclusão escolar do aluno com necessidades educativas especiais na escola comum. 2002. Dissertação (Mestrado) - Universidade de São Paulo, São Paulo.

MILES, S. Overcoming resource barriers. In INTERNATIONAL SPECIAL EDUCATION CONGRESS, 2000, Manchester. Disponível em: <http:/ / www.isec2000.org.uk. Acesso em: 15 de novembro de 2002.

PATO, T. R., SOUZA, D. R., LEITE, H. P. Epidemiologia da paralisia cerebral. Acta Fisiátrica, v.9, n. 2, p. 71-76, 2002.

SADEK, F. M., SADEK, R. Attitudes towards inclusive education in Egypt \& implications for teachers preparation and training. INTERNATIONAL SPECIAL EDUCATION CONGRESS, 2000, Manchester. Disponível em: <http:/ / www.isec2000.org.uk. Acesso em: 15 de novembro de 2002.

STANCIC, Z. Teacher's attitudes toward teaching as a determinant of their readiness for additional professional special education. INTERNATIONAL SPECIAL EDUCATION CONGRESS, 2000, Manchester. Disponível em: <http:/ / www.isec2000.org.uk. Acesso em: 15 de novembro de 2002.

UNESCO - United Nations Educational, Scientific and Cultural Organization (1994). The Salamanca Statement and Framework for Action on Special Needs Education. Salamanca. Disponível em: <http://www.unesco.org/education/pdf/SALAMA_E.PDF. Acesso em: 17 de dezembro de 2002.

. United Nations Educational, Scientific and Cultural Organization (1990). World Declaration on Education for All. Jomtien. Disponível em: <http:/ / www.unesco.org/education/ information/nfsunesco/pdf/JOMTIE_E.PDF. Acesso em 17 de dezembro de 2002. 
GOMES, C.; BARBOSA, A. J. G.

UNESCO - Universal Declaration of Human Rights (1948). Paris. Disponível em: <http:// www.un.org/Overview/rights.html. Acesso em: 17 de dezembro de 2002.

WOODRUM, D. T., LOMBARDI, T. Challenges of responsible inclusion: attitudes and perceptions of parents, teachers, psychologists and administrators. INTERNATIONAL SPECIAL EDUCATION CONGRESS, 2000, Manchester. Disponível em: <http:// www.isec2000.org.uk. Acesso em: 15 de novembro de 2002.

Recebido em 09/04/2006

Reformulado em 30/04/2006

Aceito em 30/04/2006 